\title{
Correction to: Moving beyond the mirror: relational and performative meaning making in human-robot communication
}

\author{
Petra Gemeinboeck ${ }^{1,2} \cdot$ Rob Saunders ${ }^{3}$
}

Accepted: 26 July 2021

๑) Springer-Verlag London Ltd., part of Springer Nature 2021

\section{Correction to: AI \& SOCIETY}

https://doi.org/10.1007/s00146-021-01212-1

The original version of this article unfortunately contained a mistake. The word "I* MERGEFORMAT" was introduced in the article inadvertently. However, it is now corrected.

The original article has been updated.

Publisher's Note Springer Nature remains neutral with regard to jurisdictional claims in published maps and institutional affiliations.

The original article can be found online at https://doi.org/10.1007/ s00146-021-01212-1.

Rob Saunders

r.saunders@liacs.leidenuniv.nl

Petra Gemeinboeck

petra.gemeinboeck@uni-ak.ac.at

1 Department of Media Theory, University of Applied Arts

Vienna, Vienna, Austria

2 Centre for Transformative Media Technologies, School of Arts, Social Sciences and Humanities, Swinburne University of Technology, Melbourne, Australia

3 Leiden Institute of Advanced Computer Science, Leiden University, Leiden, The Netherlands 